\title{
Accuracy of sand beach topography surveying by drones and photogrammetry
}

\author{
Elisa Casella ${ }^{1}$ (1) $\cdot$ Jan Drechsel $^{2} \cdot$ Christian Winter $^{3} \cdot$ Markus Benninghoff $^{3} \cdot$ Alessio Rovere $^{2}$
}

Received: 23 July 2019 / Accepted: 6 January 2020 / Published online: 23 January 2020

(C) The Author(s) 2020

\begin{abstract}
Beaches are characterized by high morphodynamic activity, and high-frequency measurements are needed to understand their states and rates of change. Ideally, beach survey methods should be at once accurate, rapid and low-cost. Recently, unmanned aerial systems (drones) have been increasingly utilized to measure beach topography. In this paper, we present a review of the state of art in drones and photogrammetry for beach surveys and the respective achieved measurement quality (where reported). We then show how drones with a minimal configuration and a low-cost setup can meet the high accuracy and rapidity required for beach surveys. To test a minimal drone and ground control point configuration, we used consumer-grade equipment to perform the same flight path with different cameras and at different altitudes. We then used photogrammetry to produce digital elevation models of the beach. Using a GNSS-RTK system, we collected 2950 independent control points to evaluate the accuracy of the digital elevation models. Results show that, once a few potential sources of uncertainties in the final digital elevation model are taken into account, the average RMSE(z) of the digital elevation models was $\sim 5 \mathrm{~cm}$, with a survey efficiency of ca. $3 \mathrm{~m}^{2} \mathrm{~min}^{-1}$. Digital elevation models taken at different times were used to calculate the before-after sediment budget following a storm that hit a sandy coast in Sylt Island at the German North Sea coast.
\end{abstract}

\section{Introduction}

Coastal environments and, in particular, beaches are rapidly evolving systems, driven by the continuous interaction of the topography and transport processes with wind, wave and tidal forcing. In order to understand and quantify coastal morphodynamics, it is necessary to acquire high-resolution data on beach topographic changes. The common in situ monitoring method for the measurement of beach topography (especially at small scales, up to few hundred meters of coastline) are cross-

Electronic supplementary material The online version of this article (https://doi.org/10.1007/s00367-020-00638-8) contains supplementary material, which is available to authorized users.

Elisa Casella

elisacasellaphd@gmail.com

1 ZMT, Leibniz Centre for Tropical Marine Research, Bremen, Germany

2 MARUM - Center for Marine Environmental Sciences, University of Bremen, Bremen, Germany

3 Institute of Geosciences, Christian-Albrechts University Kiel, Kiel, Germany shore GNSS-RTK (Global Navigation Satellite System-Realtime Kinematic) surveys, which can result in highly accurate information along the measured transects (Harley et al. 2010).

In the last decade, UAS (Unmanned Aerial System)-based photogrammetry has become a common tool for topographic surveying (Eisenbeiss 2009). This method has been employed in many environments, from polar to tropical regions (e.g. Dąbski et al. 2017; Ryan et al. 2015; Casella et al. 2017; Chirayath and Earle 2016). Recent studies have shown that the cost of acquiring topographic data with traditional in situ techniques is comparable with the cost of UASphotogrammetry (Mancini et al. 2013). Thus, drones are rapidly becoming standard survey tools (Moloney et al. 2018): Once few simple steps are followed (see Figure 5 in Joyce et al. 2018), acquiring high-resolution data with drones is safe, straightforward and cost-effective.

Drones allow gathering multi-temporal data that can then be analyzed to assess the spatio-temporal evolution of erosional and depositional processes (e.g. Casella et al. 2016; see also Table 1). Beach environments, however, are particularly challenging for the photogrammetric methods as the low texture and contrast of the sand surface make it harder to match distinct features between different images (Eltner et al. 2015). As such, drone-based topographic reconstructions of beach 


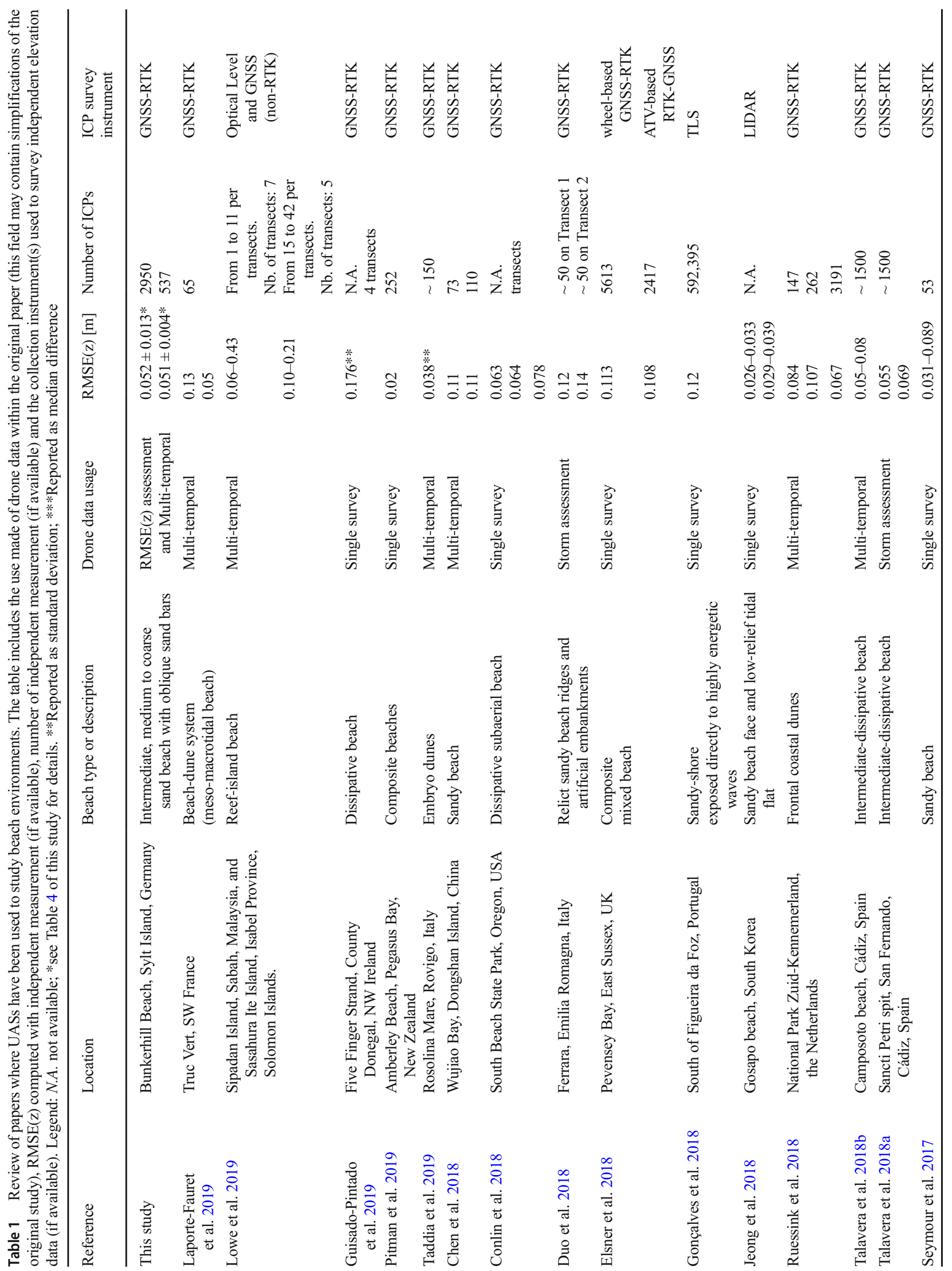




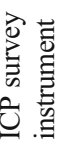

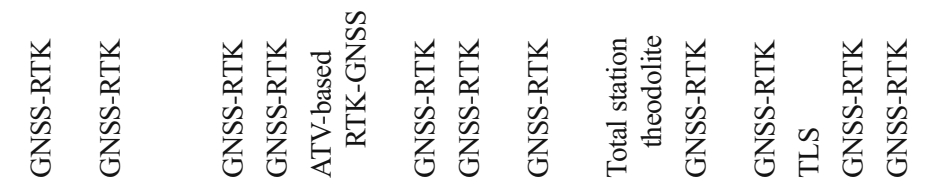

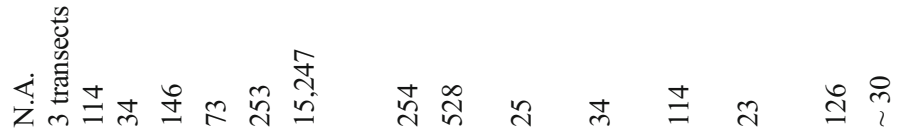

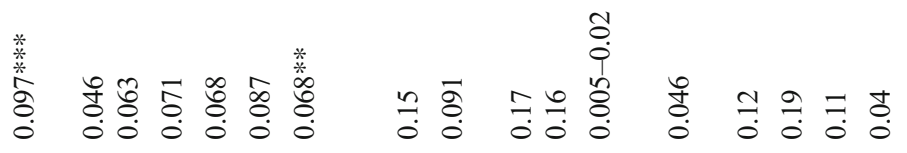

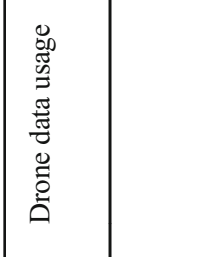

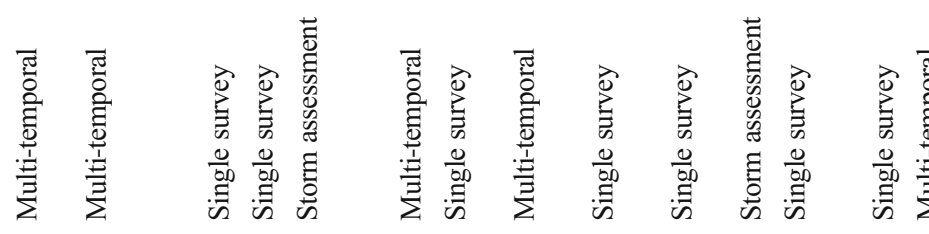

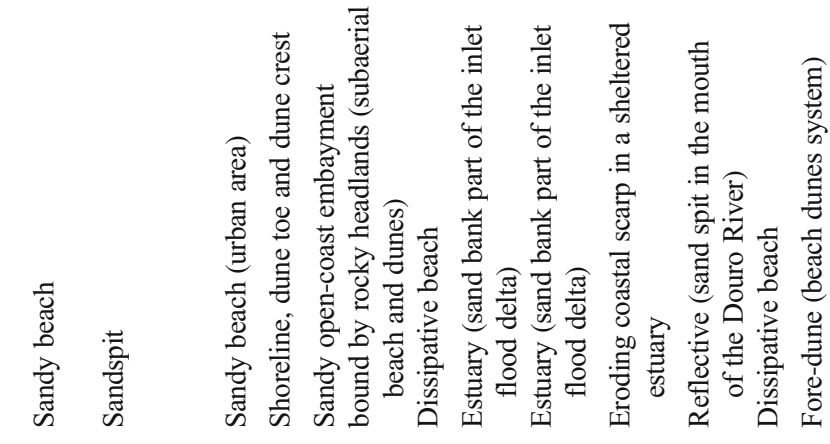

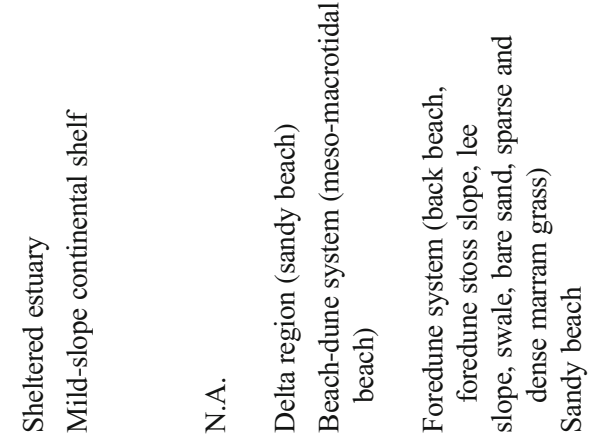

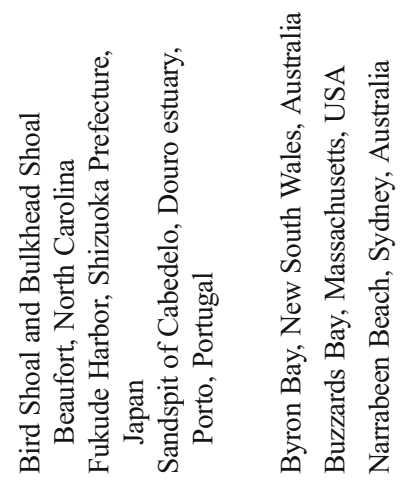

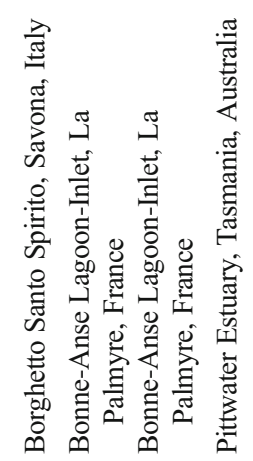

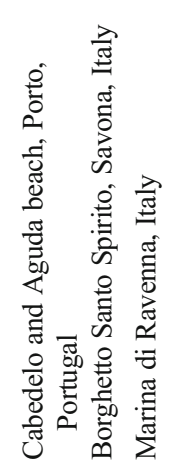

呐

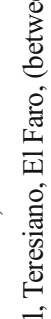

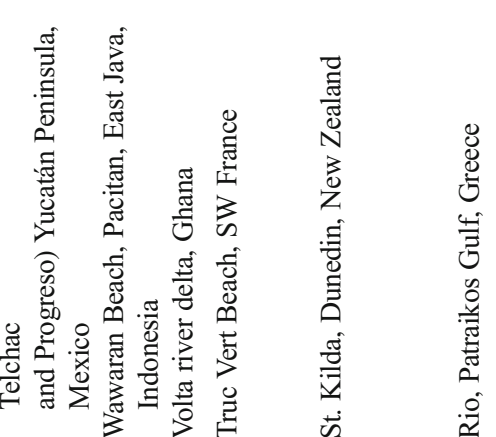

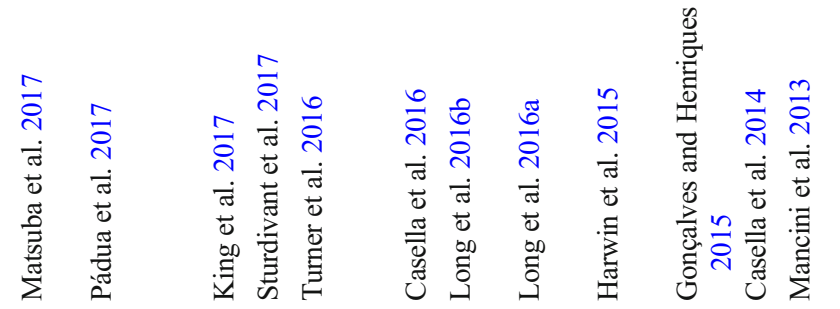

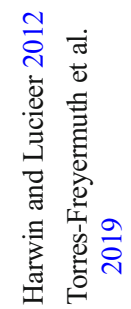

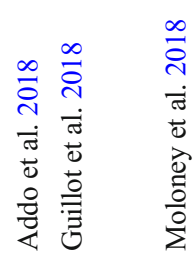

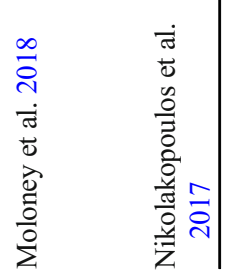




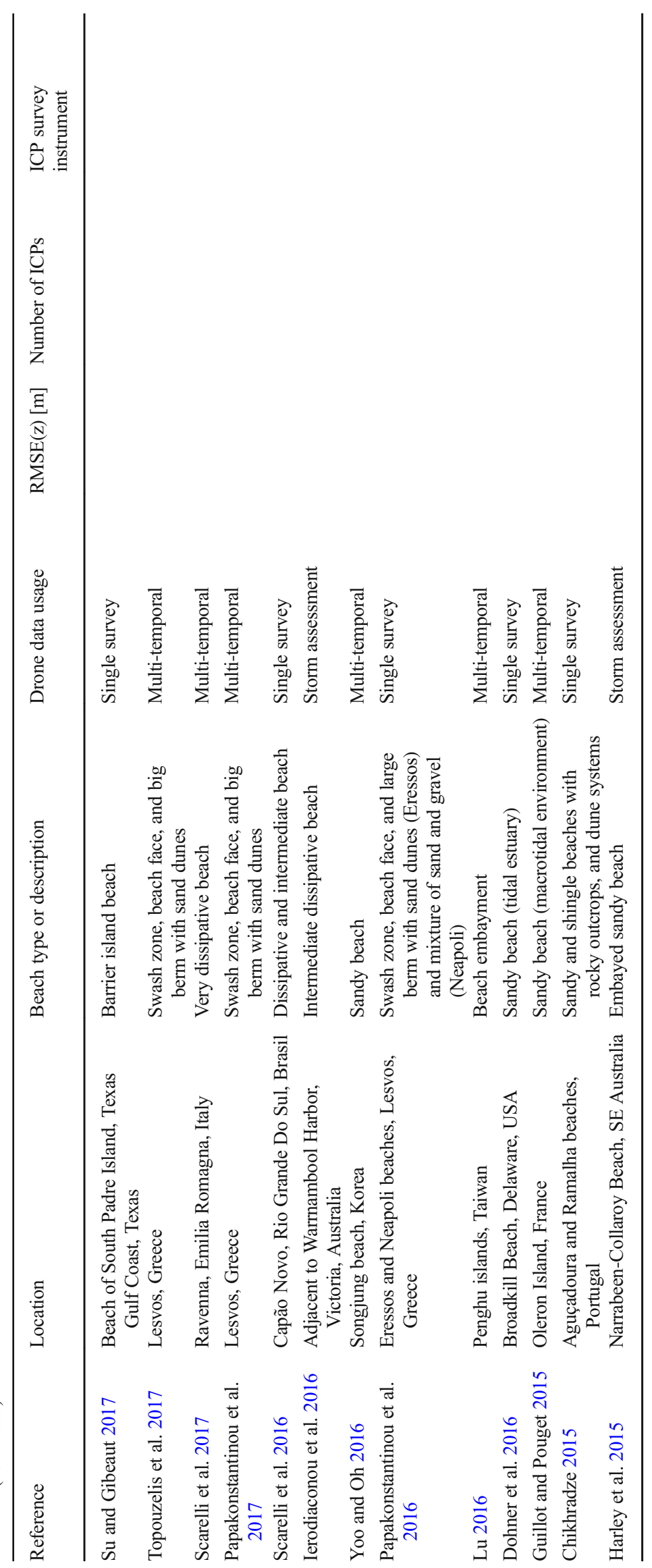


environments are often regarded as less accurate than those carried out in other geomorphic settings, such as geological outcrops or landslides.

In this study, first a short review on the quality of UAS beach topography measurements is presented. Second, for an exemplary beach domain, it is shown that, with minimal drone survey configuration, using low-cost equipment and small survey effort, it is possible to obtain highly accurate digital elevation models (DEMs) with an overall acquisition and elaboration efficiency of $3 \mathrm{~m}^{2} \mathrm{~min}^{-1}$. This method is exemplified on datasets before and after a storm at Bunkerhill beach, Sylt Island, Northern Germany.

\section{Literature review on drone-based beach topography}

The use of UAS for the study of beach environments has increased exponentially in the last 5 years. In Table 1, we present a compilation of 47 papers where UAS were used to survey beaches. Overall, $52 \%$ of the works reviewed have been conducted in the European continent, the rest equally divided (15\%) between the Australian, Asian and American continents. Only one study was conducted in Africa. The majority of the works focused on multi-temporal studies (about 60\%,
Fig. 1 a Geographic location of the study area. b The beach area surveyed and the track of a typical flight of the drone. c

Measurement of GCPs. d

Measurement of ICPs, with RTKGPS mounted on a sled

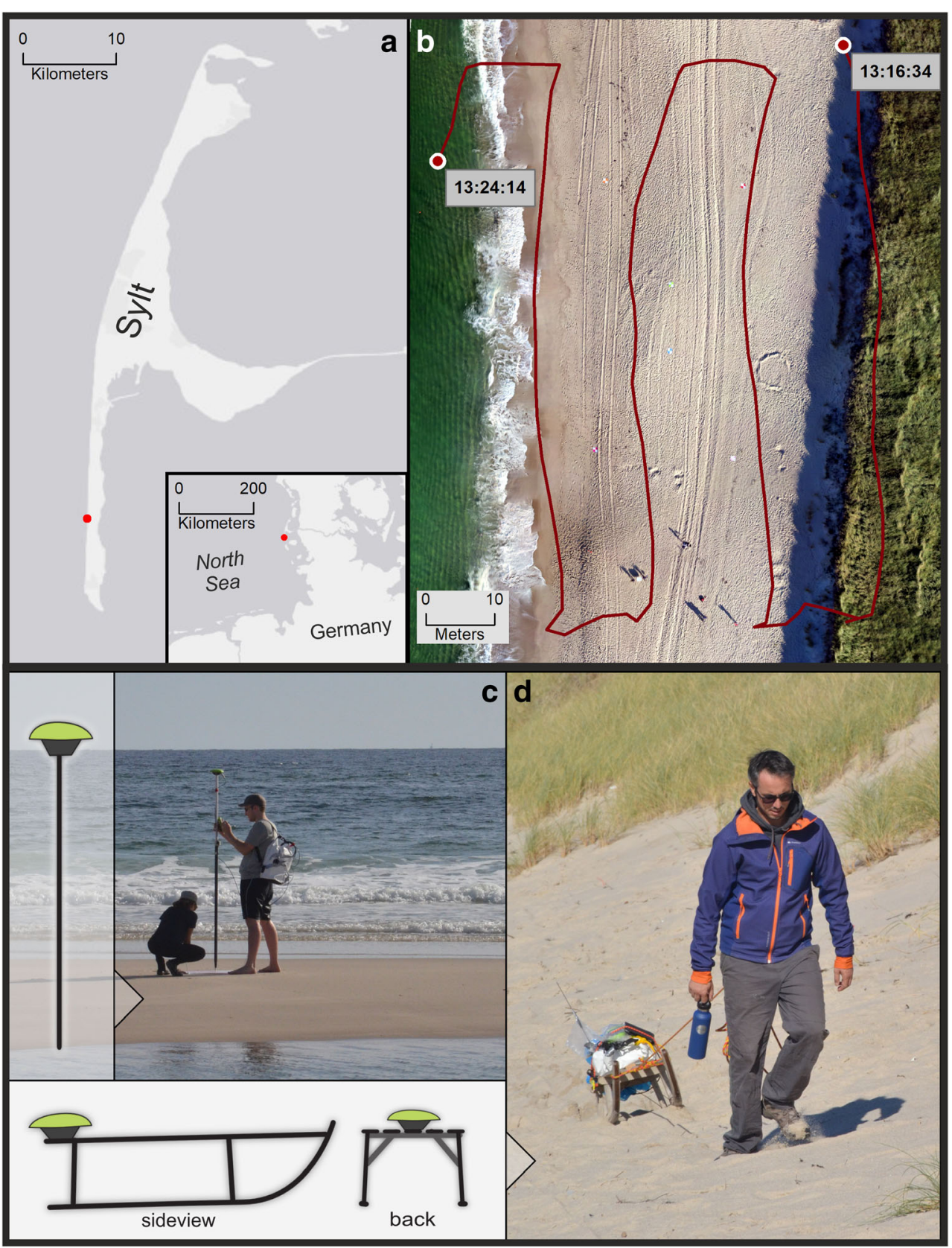


Table 2 Cameras used in this study

\begin{tabular}{llllll}
\hline Camera & Field Of view & Megapixels & $\begin{array}{l}\text { Resolution } \\
{[\mathrm{pix}]}\end{array}$ & Sensor size [mm] & Weight [g] \\
\hline Canon PowerShot S100 & $71^{\circ}$ & 12 & $4000 \times 3000$ & $7.6 \times 5.7$ & 198 \\
GoPro HERO4 Silver & $171^{\circ}$ & 12 & $4000 \times 3000$ & $6.2 \times 4.6$ & 83 \\
GoPro HERO4 Black & $80^{\circ}$ & 12 & $4000 \times 3000$ & $6.2 \times 4.6$ & 88 \\
\hline
\end{tabular}

including post-storm assessment studies) to monitor sediment displacement on the coast. 28 studies report the quality of the digital elevation models (DEM) derived from drone data and photogrammetry by comparison with independent measurements. In general, the instruments used to collect independent elevation measurements are mainly GNSS-RTK, LIDAR, TLS or total station. The highest accuracy (RMSE $=0.005 \mathrm{~m}$ ) was achieved by using a total station to define the ground control points (GCP) for the calibration of the data and a limited set $(n=34)$ of independent control points (ICPs) for the quality assessment. Three studies used high-density point clouds (e.g. LIDAR and terrestrial laser scanning TLS) for comparisons. In those, RMSE ranged between 0.026 and $0.12 \mathrm{~m}$. Almost $90 \%$ of the reviewed works used GNSS-RTK to measure ICPs. The number of ICPs varies among the different works, and only few of them (5 works) collected a high number of ICPs (more than 1000). Among these, the range of the accuracy of the DEMs varies between 0.05 and $0.11 \mathrm{~m}$. The GNSS-RTK method to measure ICPs has an intrusive nature, which is discussed in "Systematic errors on beach environments." The second part of Table 1 lists literature in which no assessment of accuracy of the DEM was carried out or not enough information was given if errors were based on independent measurements.

\section{Study area and methods}

The range of UAS topographic surveying quality was intercompared with low-cost surveys carried out with different settings and systems at the North Sea coast. The investigated area is a beach patch along the Bunkerhill beach-dune system, located in the southern part of the island of Sylt (Wadden Sea, North Germany; Fig. 1a). The surveyed beach area measures $120 \mathrm{~m}$ along-shore and $50 \mathrm{~m}$ cross-shore, extending from the upper part of the swash zone ( $2 \mathrm{~m}$ above mean sea level) to the foot of the dune (ca. $10 \mathrm{~m}$ above mean sea level) (Fig. 1b). To collect aerial data, we used a DJI Phantom 2 quadcopter. The approximate take-off weight of the UAS during the experiment was about $1300 \mathrm{~g}$. We programmed a mowing-lawn flight plan into the native Phantom DJI app, "DJI Ground Station."

The same flight path was performed (Fig. 1b) with different cameras and at different altitudes. A Canon S100 was used at altitudes of 30, 40 and $50 \mathrm{~m}$ above ground level. Two additional flights at $50 \mathrm{~m}$ above ground level were carried out with a GoPro Hero 4 Silver rolling shutter fisheye lens and a GoPro HERO4 Black modified to yield a similar field of view (FOV) as consumer-grade compact cameras (focal Length $5.4 \mathrm{~mm}$, horizontal opening angle $60^{\circ}$ and aperture range $\mathrm{f} / 2.5$ ). Specifications for the cameras used are given in Table 2 . Flights were carried out at constant horizontal speed of $1.0 \mathrm{~m} / \mathrm{s}$, with track lines $12 \mathrm{~m}$ apart, resulting in effective overlaps indicated in Table 3 for each flight. Pictures were taken every $5 \mathrm{~s}$ for the Canon S100 and the GoPro Hero Silver and every $2.5 \mathrm{~s}$ for the GoPro Hero Black.

As none of the cameras was connected to the flight control, picture acquisition was triggered by time intervals. Therefore, the front and side overlap was planned before each survey on the basis of flight path (including flight altitude), geometry of camera sensor, focal length, photo frequency and speed of the aircraft. A minimum front overlap of $86 \%$ and side overlap of $67 \%$
Table 3 Details on number of photos, effective overlap, tie points, DEM resolution, area covered and $\operatorname{RMSE}(z)$ resulting from each photogrammetric workflow. The RMSE(z) was calculated by Agisoft

\begin{tabular}{lllllll}
\hline Flight (camera and altitude) & $\begin{array}{l}\text { Number of } \\
\text { photos }\end{array}$ & $\begin{array}{l}\text { Effective } \\
\text { overlap }\end{array}$ & Tie points & $\begin{array}{l}\text { DEM resolution } \\
{[\mathrm{cm} / \mathrm{pix}]}\end{array}$ & $\begin{array}{l}\text { Total area } \\
\left.\text { covered [m }{ }^{2}\right]\end{array}$ & $\begin{array}{l}\text { Photoscan RMSE(z) } \\
\mathrm{Z} \text { error }[\mathrm{m}]\end{array}$ \\
\hline Canon S100 (30 m altitude) & 136 & 6.8 & 81,384 & 1.7 & 9290 & 0.011 \\
Canon S100 (40 m altitude) & 132 & 11.1 & 59,898 & 2.6 & 12,900 & 0.016 \\
Canon S100 (50 m altitude) & 137 & 11.5 & 45,305 & 3.0 & 14,600 & 0.016 \\
GoPro Hero 4 Silver (50 m altitude) & 104 & 11.6 & 29,667 & 4.0 & 49,200 & 0.006 \\
GoPro Hero 4 Black (50 m altitude) & 217 & 13.0 & 62,073 & 2.1 & 12,000 & 0.007 \\
\hline
\end{tabular}

Photoscan on the basis of GCP elevations. For detailed results for each flight, the reader is referred to the Supplementary Materials 


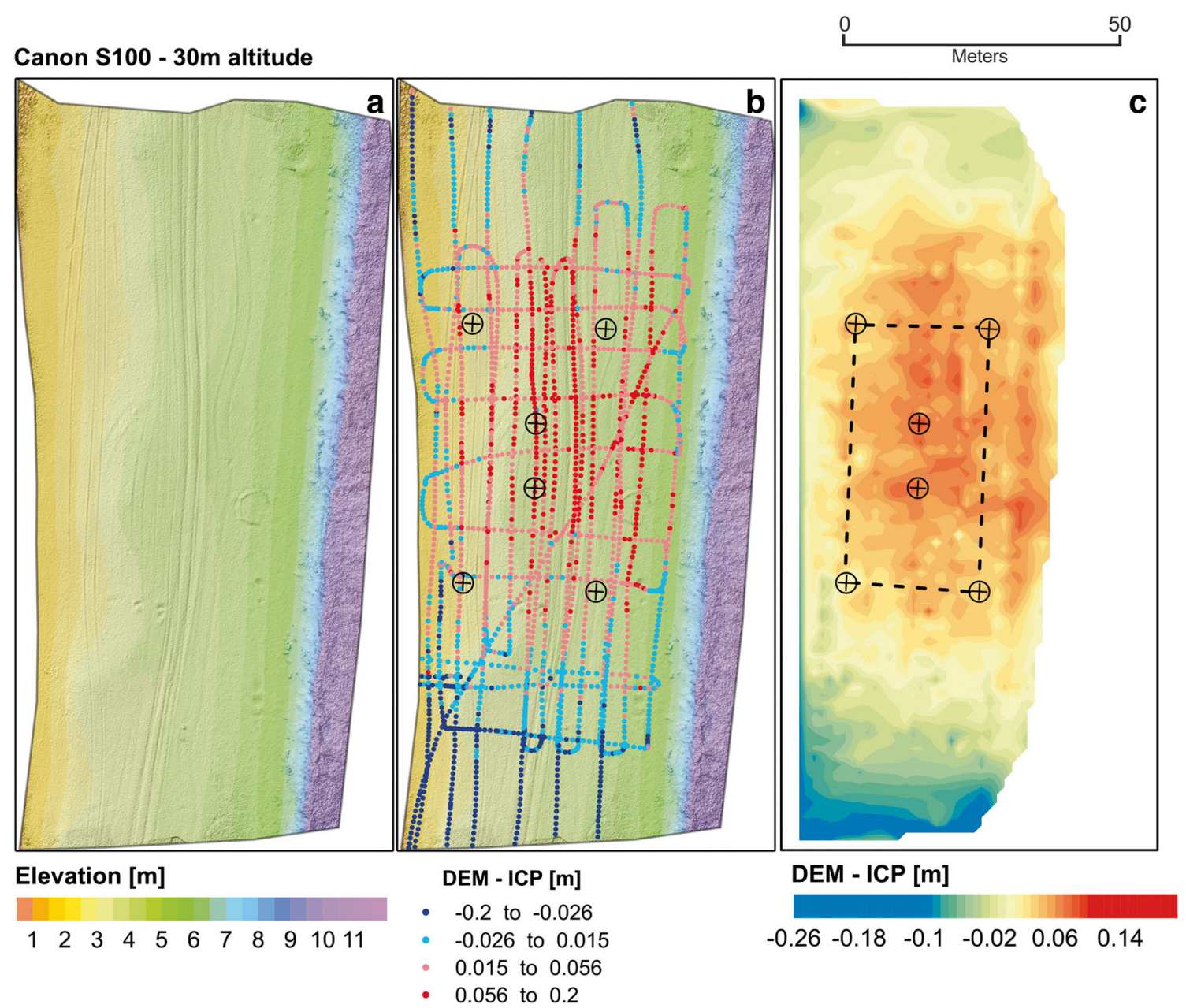

Fig. 2 a Digital elevation model (DEM) of the surveyed beach section. b Location of ground control points (GCPs, black crossed circles) and independent control points (ICPs, small dots). The color of the ICPs

relates to the difference between the elevation of the DEM and the elevation of the ICP. $\mathbf{c}$ Interpolated surface of the DEM-CP differences, created with natural neighbor algorithm

(worst case, Canon Powershot S100 flown at $30 \mathrm{~m}$ altitude) and a maximum front overlap of $90 \%$ and side overlap of $80 \%$ (best case, Canon Powershot S100 flown at $50 \mathrm{~m}$ altitude) was set.

Ground control points were measured using a JAVAD SIGMA/GrAnt G3T GPS utilizing real-time kinematic correction from an NTRIP server (HEPS service by SAPOSC). The final vertical accuracy of the GNSS points is in the range of 2$3 \mathrm{~cm}$. Six ground control points (hereafter GCPs) were placed on a 25 by $40 \mathrm{~m}$ area and measured using RTK GPS mounted on a pole (Fig. 1c). In order to have a statistically significant number of ICPs, the same RTK GPS was mounted on a snow sled and dragged along the beach while acquiring points at a frequency of $1 \mathrm{~Hz}$ (Fig. 1d). The intrusive nature of the sled method to collect ICPs is discussed in "Systematic errors on beach environments.". The locations of GCPs and ICPs are shown in Fig. 2b.

The aerial photos collected during the flights were processed using Agisoft Photoscan Pro (version 1.3.4; www.agisoft.com; now Agisoft Metashape) resulting in orthophotomosaics and digital elevation models (DEM). QGIS was used to crop the
DEMs to the area between the upper part of the swash zone and the initial part of the dune. This allowed to avoid unconformities in the DEM reconstruction due to wave swash in the scene. The DEMs were also cropped to match the least extent flight path acquired with the narrow-angle Canon S100 at $30 \mathrm{~m}$ altitude. Matlab® scripts were developed to compare the elevation values of ICPs and the elevation of DEMs at the same points. In general, alignment parameters were set to "high," dense point cloud generation was executed with "high" settings and depth filtering mode set to "aggressive." The dense cloud was the source used to build the DEMs with interpolation enabled. All XY coordinates in this study refer to ETRS89/UTM Zone 32N, while heights are given relative to MSL (EGM96). The scripts used are available at DOI: https://doi.org/10.5281/ zenodo.3549893, and the detailed reports of Agisoft Photoscan are annexed in the Supplementary Materials.

A comparative measure of the efficiency was defined taking into account the following: (i) the placement and GPS positioning of the six GCPs and the pre-flight checks (mobilization time); (ii) flight time (aerial data acquisition time); and 
Table 4 Results of the comparison between DEM values and ICP elevations for the entire ICP dataset ( $n=2950$ points) and the subset of ICPs included within the area delimited by the GCPs $(n=537$, dashed line in Fig. 2c).*See also right panels in Fig. 4, black lines. **See also right panels in Fig. 4, orange lines. Average and standard deviation values are shown at the bottom of the table in italics

\begin{tabular}{|c|c|c|c|c|}
\hline \multirow[b]{2}{*}{ Flight } & \multicolumn{2}{|c|}{ All ICPs $(n=2950)$} & \multicolumn{2}{|c|}{ ICPs Internal to GCPs $(n=537)$} \\
\hline & $\begin{array}{l}\text { Average } \\
\text { DEM - ICP } \\
{[\mathrm{m}]^{*}}\end{array}$ & $\begin{array}{l}\text { RMSE(z) ICPs } \\
{[\mathrm{m}]}\end{array}$ & $\begin{array}{l}\text { Average } \\
\text { DEM - ICP } \\
{[\mathrm{m}]^{* *}}\end{array}$ & $\begin{array}{l}\text { RMSE(z) } \\
{[\mathrm{m}]}\end{array}$ \\
\hline Canon S100 (30 m altitude) & 0.015 & 0.045 & 0.052 & 0.055 \\
\hline Canon S100 (40 m altitude) & -0.023 & 0.075 & 0.049 & 0.053 \\
\hline Canon S100 (50 m altitude) & 0.002 & 0.048 & 0.050 & 0.053 \\
\hline $\begin{array}{l}\text { GoPro Hero } 4 \text { Silver ( } 50 \mathrm{~m} \\
\text { altitude) }\end{array}$ & 0.044 & 0.051 & 0.044 & 0.046 \\
\hline $\begin{array}{l}\text { GoPro Hero } 4 \text { Black ( } 50 \mathrm{~m} \\
\text { altitude) }\end{array}$ & 0.029 & 0.044 & 0.047 & 0.050 \\
\hline Average & 0.013 & 0.052 & 0.048 & 0.051 \\
\hline Standard deviation & 0.026 & 0.013 & 0.003 & 0.004 \\
\hline
\end{tabular}

(iii) GPS data post process and photogrammetry workflow (elaboration time).

A pre-post storm UAS flight to map the effect of an extreme event was performed using the Canon S100 camera and flying the drone at $50 \mathrm{~m}$ above ground level. As, in these flights, a large area was considered, $10 \mathrm{GCPs}$ were placed per flight instead of the 6 GCPs used for the accuracy assessment.

\section{Results}

\section{Accuracy assessment}

The number of photos collected during the UAS surveys varied from 104 to 217 (the latter for the Go Pro Hero 4 Black, acquiring at $0.4 \mathrm{~Hz}$ versus all the other cameras acquiring at $0.2 \mathrm{~Hz}$ ). Data on the effective overlaps, number of tie points, DEM resolution and total area covered for each flight are reported in Table 3. The effective overlap represents the average number of projections for each point in the sparse point cloud. Tie points are points clearly identifiable in two or more images. They are selected as reference points. The resolution of the DEMs varied between 1.7 and $4.0 \mathrm{~cm} / \mathrm{pix}$. The RMSE (z error) varied between 0.006 and $0.016 \mathrm{~m}$.

Figure 2a shows a visualization of a DEM obtained from the flight with the Canon S100 camera flying at a constant altitude of $30 \mathrm{~m}$ above ground level. The six GCPs and the 2950 ICPs surveyed with the RTK GPS system are shown in Fig. 2b. The full comparison results and the Agisoft processing reported for each flight are attached as Supplementary Materials to this paper.

The individual DEMs were compared with the ICPs surveyed with RTK GPS. All results of this comparison are shown in Table 4 and rendered graphically in Fig. 4.

\section{Pre-post storm assessment}

Bunkerhill beach is exposed to westerly winds and waves, and beach morphology is mainly driven by storms; also, beach nourishments are carried out on a regular basis. The effect of single storms on beach dynamics is of scientific and management interest (Blossier et al. 2017). In order to assess the morphological effects of a storm event, two surveys were performed on Sept 26th and on October 4th, 2016 at MLW (mean low water) to allow for maximum beach coverage. Details of each flight (including location of GCPs inside the area of interest) are contained in the Agisoft Photoscan reports annexed as Supplementary Materials to this article.

A storm event started (after 4 days of previously calm wave conditions) on the morning of Sept. 27th, 2016 (Fig. 3d). Wind speed increased from $2.8 \mathrm{~m} \mathrm{~s}^{-1}$ during the survey to ca. $3.8 \mathrm{~m} \mathrm{~s}^{-1}$ for the following days from SWS to W (source: German Meteorological Office DWD). During that time, waves with significant height of 2-3 m (max wave height $3.6 \mathrm{~m}$ ) were measured offshore for a time span of roughly $72 \mathrm{~h}$. Average wave period increased from 4.3 to $7.4 \mathrm{~s}$ (source: Federal Maritime and Hydrographic Agency of Germany (BSH), via COSYNA Data web portal).

The storm event caused changes in the beach morphology, which can be observed in the orthophotomosaics before and after the storm (Fig. $3 \mathrm{a}, \mathrm{b}$ ). The shoreline (countour line at msl extracted from the DEM) evolved from its initial position before the storm (dotted line in Fig. 3) to the post-storm position (continuous line in Fig. 3b). From the comparison of the two orthophotos (Fig. 3a, b), it is possible to discern that the two sandbars in front of the beach migrated northwards by around $30 \mathrm{~m}$. The rip channel between these longshore parallel bars was also wider (and possibly 

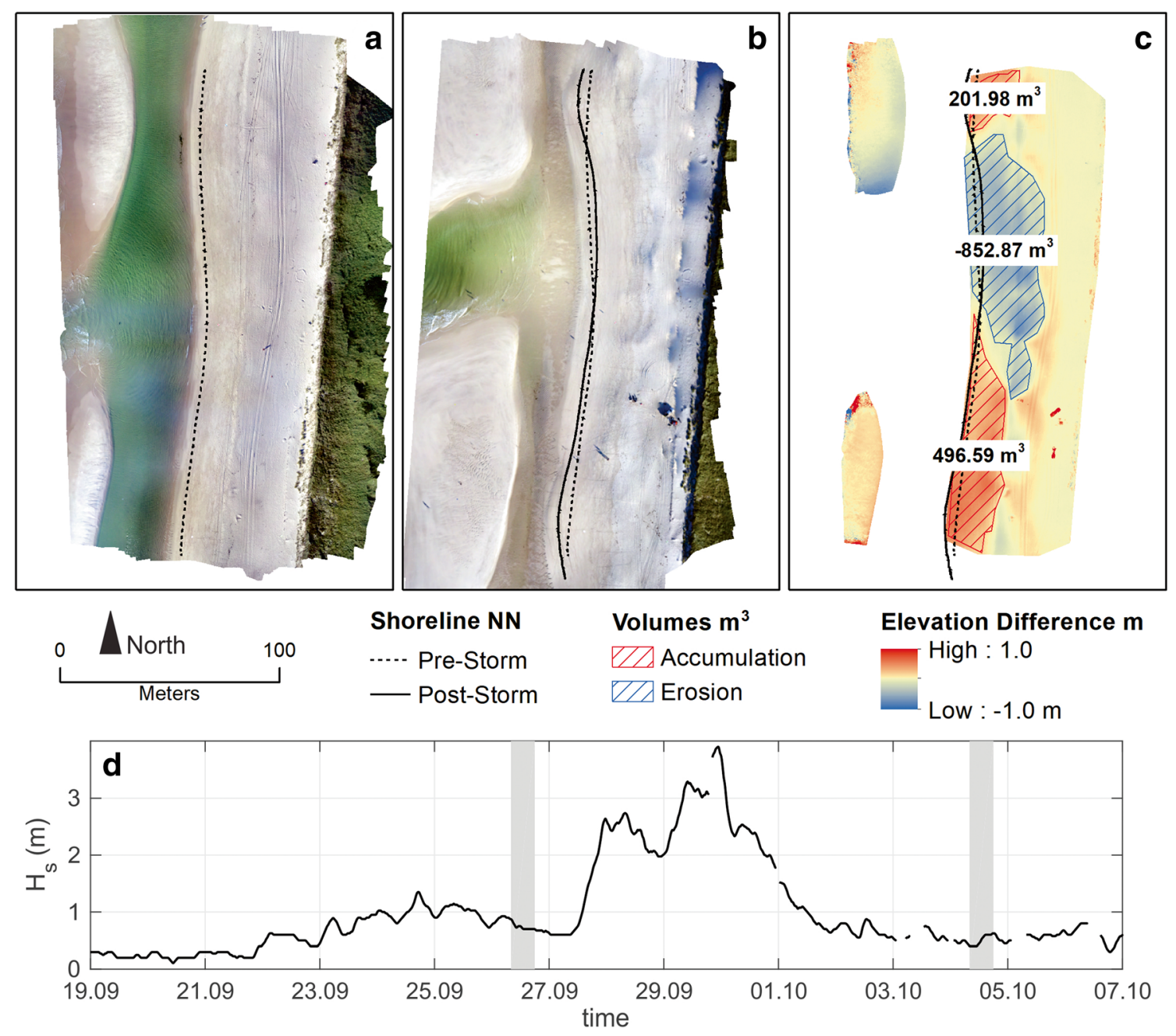

Fig. 3 a Orthophotomosaic derived from the survey of the 26th September 2016 and the countourline at msl (dotted line) extracted from the DEM of the same survey (before the storm event). $\mathbf{b}$ The same from 4th October 2016 and countour lines before (dotted line) and after

deeper) after the storm, while the longshore parallel channel between the bars and the coastline appears narrower (and possibly shallower).

Subtracting the pre-post storm DEMs (Fig. 3c), beach morphological changes and areas and volumes of erosion (blue in Fig. 3c) and accretion (red in Fig. 3c) along the beach are measured. The area on the beach around the channel deepened by ca. $40 \mathrm{~cm}$, and the bar located north of the channel was subject to ca. $40 \mathrm{~cm}$ erosion. On the contrary, the south part of the beach (south red patch, Fig. 3 ) and the south bar underwent an aggradation of ca. 40$60 \mathrm{~cm}$. Comparing only the area in common between the two flights, the volume eroded on the beach front (excluding the offshore bars) was ca. $852 \mathrm{~m}^{3}$, in the area in front of the channel separating the two offshore bars. In the areas immediately North and South of this area (Fig. 3c), a deposition of ca. $698 \mathrm{~m}^{3}$ of sand was recorded, with a total loss of sand of ca. $154 \mathrm{~m}^{3}$, over a total surveyed (continuous line) the storm event. $\mathbf{c}$ Difference in elevation between the DEM before and after the storm. d Significant wave height (BSH via COSYNA Data web portal). The gray bands represent the pre-post flight times

beach area (excluding the bars) of about $11,000 \mathrm{~m}^{2}$. The foot of the dune was not subject to major changes.

\section{Discussion}

\section{UAS and survey configuration}

The UAS configuration described above is a low-cost solution (see a quantification of the hardware and software costs in Table 5), which should be affordable by most earth science laboratories. The DJI Phantom 2 was first released in December 2013, therefore can be considered at least two generations behind modern drones, but it still represents a reliable low-cost platform able to provide high-resolution and accurate data. In the configuration we used, the drone does not even include a built-in camera connected with the drone electronics. Compared with more modern solutions, this drone presents 
Table 5 Quantification of the hardware and software costs. *The cost reported refers to a DJI Phantom 4 pro v.2.0, which is the "DJI Phantom" model in production as of December 2019. The value of the DJI Phantom 2 used in this work is approx. 500 euro and the cost of a Canon S100 is 240 euro. Therefore, the total cost sustained to obtain the results illustrated in this study is approx. 1490 euros. Note: Costs are indicative and refer to market prices at the time of writing (December 2019). Drone costs are extremely variable in time

\begin{tabular}{ll}
\hline Description & Approx. Cost (euro) \\
\hline DJI Phantom* & 1700 \\
Tablet & 250 \\
Metashape Agisoft Pro Edu & 500 \\
Total cost (UAS platform plus & 2450 \\
photogrammetric software) & \\
\hline
\end{tabular}

the advantage to have a relatively large space under the main body of the copter, which allows mounting different cameras with or without a gimbal. Equipped with a BTU Bluetooth module, the Phantom 2 can be connected to a mobile device where flights can be programmed with the native Phantom DJI app, "DJI Ground Station," that allows programming a flight path but, as described above, does not allow automated calculation of front and side overlap of the resulting photos. This information can be easily obtained knowing the geometry of the camera sensor and few other parameters as described above.

For this study, six ground control points (GCP) were placed in a $25 \times 40 \mathrm{~m}$ area (dashed lines in Fig. $2 \mathrm{c}$ ). This part of the DEM is referred to as "Internal to the GCPs" in contrast to the entire survey area, located outside of the dashed line in Fig. 2c. In the area internal to GCPs, we placed six targets, four at the edges and two at the center. In an area of similar dimensions, Harwin et al. (2015) used a similar spatial configuration on 5 and 13 GCPs and found a difference of only few millimeters between the final DEMs accuracy (see their Table 3, products "Self13GCP22mm" and "Self5GCP22 $\mathrm{mm}$ " that are more comparable with our study design). In general, though, the number and location of GCPs should be evaluated before the survey, in order to not underestimate the number of needed GCPs. An example of such evaluation is provided by Laporte-Fauret et al. (2019) who, working on a $350 \times 1000 \mathrm{~m}$ beach, stated that "the use of 5 CGPs [..] is the minimum requirement in order to reach satisfactory accuracy with a RMS_Z error."

\section{Doming of the scene}

Mapping the difference between DEM and ICP elevations (Fig. 2c), it is evident that, beyond the extent of the area delimited by the GCPs, the topographic reconstruction is subject to a doming effect (Fig. 4). The reasons for this effect originate in the photogrammetric process, as described by
James and Robson (2014): Structure from motion (SfM) reconstructions of regular linear patterns of images cannot compensate for radial lens distortions accurately when camera self-calibration is necessary. This fact causes a DEM deformation, which can be reduced by adding oblique imagery or with a suitable distribution of control points in the surveyed area.

The doming effect on the DEMs is evident in all flight constellations (Fig. 4), and it does not change with altitude when using the Canon S100. The doming appears greatly diminished at $50 \mathrm{~m}$ altitude with both GoPro cameras. In the central area of each DEM (dashed lines in Fig. 2c), delimited by the GCPs (orange points in Fig. 3, left panels), the doming is reduced.

As a result of the doming effect, different results must be expected when comparing the entire survey area with the area internal to the GCPs (Table 4). In fact, the average difference between DEMs in the entire study area (Gaussian curves in black, Fig. 4 right panels) is $0.013 \pm 0.026 \mathrm{~m}$. For comparison, the average difference between different DEMs when only considering the area internal to the GCPs (Gaussian curves in orange, Fig. 4 right panels) is $0.048 \pm 0.003 \mathrm{~m}$. It is important to note that the standard deviation of the DEM-ICP elevation difference is one order of magnitude smaller when considering the area internal to the GCPs. This is also true when comparing the RMSE(z) among different DEMs that has the same average but shows a significantly lower standard deviation between different flight and camera configurations when only the area internal to the GCPs is considered.

\section{Systematic errors on beach environments}

Results (Table 4; Fig. 4) indicate that for the area that is not affected by doming (i.e. the area internal to the GCPs), the RMSE(z) between DEM and ICPs elevation are similar for all flight and camera configurations $(0.051 \pm 0.004 \mathrm{~m})$. DEM obtained from the UAS flights are about $5 \mathrm{~cm}$ higher than the ICPs. This is a systematic error, which originates under every survey set-up: GCPs were measured with the RTK-GPS mounted on a survey pole; the ICPs were measured with the GPS mounted on a sled (Fig. 1d). Due to the soft sand, it is possible that the sled was digging few centimeters while being dragged. This interpretation is supported by the circumstance that three GCPs located less than half meter from the closest ICP are systematically higher by a range of 6 and $10 \mathrm{~cm}$. Despite a possible variance in beach surface properties (i.e. wet vs. drier beach and finer vs. coarser sand), leading to different vertical sinking of the sled, this error may be considered as systematic and constant throughout surveys. In spite of this statement, the data presented in this work are not corrected against this systematic error since further research could asses this error based on different sedimentological properties of the beach. Similar systematic errors were already highlighted by Talavera et al. (2018a) and Gonçalves and Henriques (2015) 
Fig. 4 Left panels: Plot of DEMICP difference versus distance from the GCP centroid, located at the center of the scene. The orange dots indicate the area inside the GCP boundaries. The blue line represents a secondorder polynomial trough the points. Right panels: Gaussian distribution of the DEM-ICP difference for the entire scene (black line) or for the area within the GCPs (orange line). Numbers indicate the average DEM-ICP value, in meters
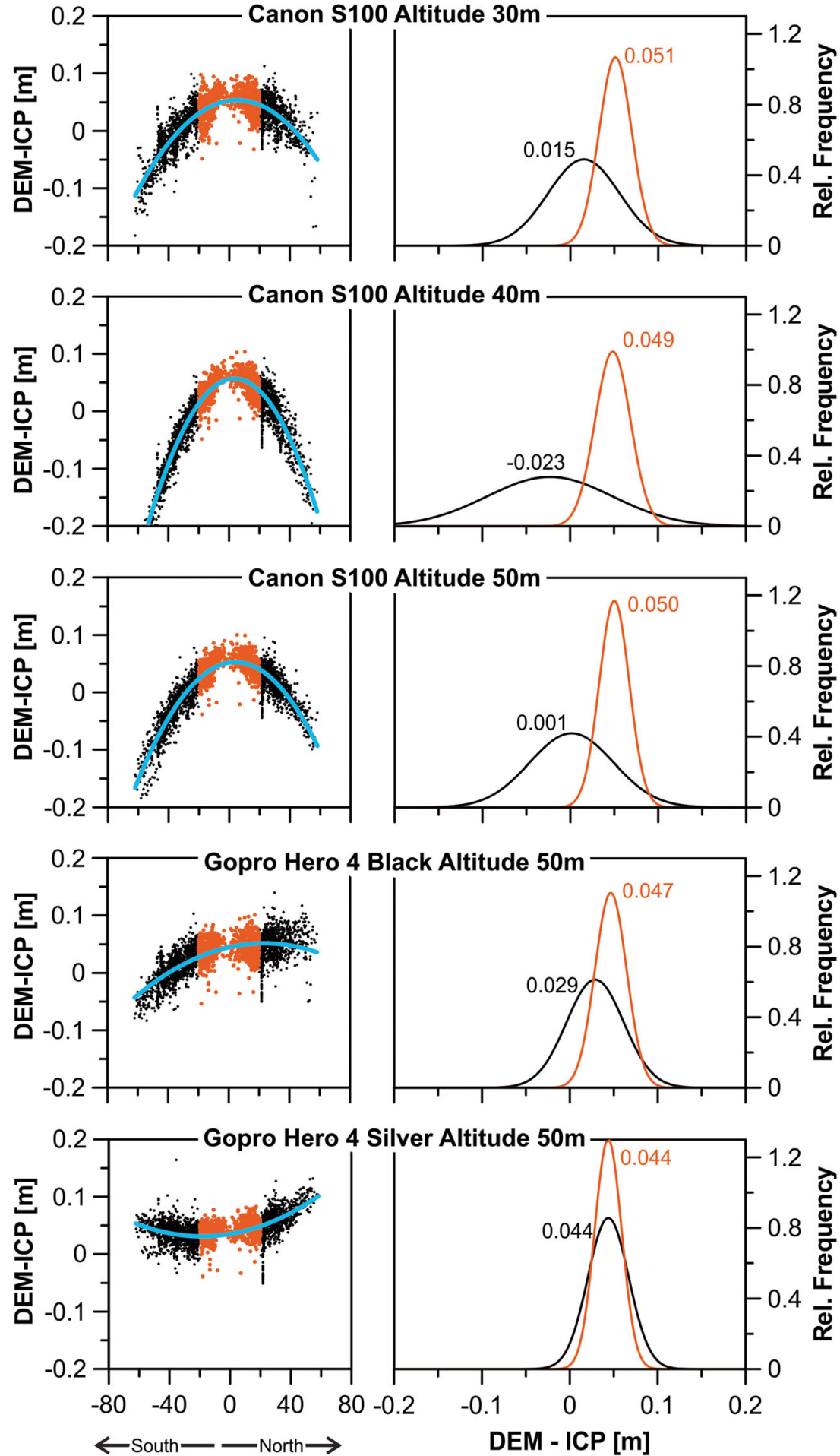

Distance from GCP centroid [m]

who found, respectively, positive biases of up to $5 \mathrm{~cm}$ and up to $7.5 \mathrm{~cm}$ in comparing GPS measurement and drone values on sandy beaches. Both studies used similar techniques than those used in this study to measure GCPs and ICPs. For example, Talavera et al. (2018a, b) used a pole to measure
GCPs, but, for the collection of ICPs, the GNSS survey system was instead mounted on a backpack. The weight on the sand of the operator carrying the GPS during the ICP measurements was considered the source of the systematic error following the same rationale we illustrate above. Also Pitman 
et al. (2019) highlighted the intrusive nature of the RTKGNSS methods (vehicle mounted and pedestrian), which alter the beachface by sinking into the sand in contrast to the noninvasive nature of the UAS method.

\section{Efficiency of drone survey}

In this study, a DEM covering an area of $1000 \mathrm{~m}^{2}$ with a resolution of 1.7 to $4 \mathrm{~cm} /$ pix (Table 3 ) and RMSE(z) of $0.051 \pm 0.004 \mathrm{~m}$ (Table 4) was obtained. For methodological inter-comparison, survey efficiency can be calculated. The equipment mobilization time was about $80 \mathrm{~min}$, the aerial data acquisition time about $10 \mathrm{~min}$ and the time for analysis lasted about $270 \mathrm{~min}$. Thus, the efficiency of this UAS beach survey is about $3 \mathrm{~m}^{2} \mathrm{~min}^{-1}$. It is noted that this number is highly dependent on the flight settings. If the setup with the Canon S100 (50 m altitude) and an area of $14,600 \mathrm{~m}^{2}$ (Table 2) is considered, the survey efficiency changes to ca. $40 \mathrm{~m}^{2} \mathrm{~min}^{-1}$. The DEM in this case was affected by the doming effect described above, which should be solved placing the GCPs over a wider area, and/or adding GCPs (thus, increasing the mobilization time). The survey efficiency of the UAS-photogrammetry method described here will improve in the near future, thanks to two main technological developments. First, advancements in computer science will cut the photogrammetry processing time needed for large datasets. Second, the availability of low-cost RTK systems onboard drones has already reduced the mobilization time by reducing the number of control points needed to obtain high-accuracy DEMs for large areas (Forlani et al. 2018).

\section{Conclusions}

The results allow to highlight different aspects related to the use of UAS and photogrammetry for the monitoring of beach environments.

1. UAS-photogrammetry is used frequently for the measurement of beach topography (Table 1) as it is at once accurate, rapid and low-cost. Several studies report vertical accuracies $(\operatorname{RMSE}(\mathrm{z}))$ in the order of a few millimeters to a few decimeters.

2. It is possible to achieve a final DEM accuracy in the order of $\sim 5 \mathrm{~cm}$ using a minimal low-cost drone configuration. In this study, results did not change significantly by changing the altitude or the camera type.

3. These results are only valid for the area delimited by the GCPs. Outside of this area, a doming effect related to the photogrammetric processing of UAS photos degrades the quality of the results. This stresses the importance of careful planning the positioning of GCPs and flight path according to the area of interest to be mapped.

4. Within the area delimited by the GCPs survey (ca. $1000 \mathrm{~m}^{2}$ ), an efficiency of the DEM generation of ca. $3 \mathrm{~m}^{2} \mathrm{~min}^{-1}$ has been calculated. This may be regarded as the minimal efficiency of a drone survey on a beach environment.

5. The geometry that was adopted for the emplacement of GCPs has been successful to gather data at very high resolution within the area delimited by the GCPs. A similar GCP pattern was used to map a larger area to assess the pre-post storm morphological variations at a larger scale.

6. The analysis of derived DEMs must consider the survey method for CPs on soft sands. In fact, collecting GCPs with the GNSS mounted on a pole versus mounted on a sled for ICPs may introduce systematic errors that need to be accounted for.

7. It was shown that UAS data analyzed with photogrammetric methods can give information on beach topography with accuracy on the same order of magnitude as the most commonly used monitoring method (i.e. RTK transects). The advantages of the UAS-photogrammetry method reside in the survey efficiency (ca. $3 \mathrm{~m}^{2} \mathrm{~min}^{-1}$ ) and in the higher detail with respect to topographic transects, i.e. it allows a full reconstruction of the beach topography.

Acknowledgments We appreciate cooperation and support by the local relevant authorities LKN and LLUR. We thank one anonymous reviewer for the useful comments, which improved significantly the manuscript.

Funding information Open Access funding provided by Projekt DEAL. This research was financially supported by the Institutional Strategy of the University of Bremen, funded by the German Excellence Initiative [ABPZuK-03/2014] and by ZMT, the Centre for Tropical Marine Research.

Data availability Supplementary Materials annexed to this paper include the reports of the Agisoft Photoscan (now Agisoft Metashape) processing and supplementary figures detailing the results for each drone flight. The Matlab® scripts used to produce the comparison maps on which Figs. 2, 3 and 4 are based are available at this link: https://doi.org/10.5281/zenodo. 3580721 .

Open Access This article is licensed under a Creative Commons Attribution 4.0 International License, which permits use, sharing, adaptation, distribution and reproduction in any medium or format, as long as you give appropriate credit to the original author(s) and the source, provide a link to the Creative Commons licence, and indicate if changes were made. The images or other third party material in this article are included in the article's Creative Commons licence, unless indicated otherwise in a credit line to the material. If material is not included in the article's Creative Commons licence and your intended use is not permitted by statutory regulation or exceeds the permitted use, you will need to obtain permission directly from the copyright holder. To view a copy of this licence, visit http://creativecommons.org/licenses/by/4.0/. 


\section{References}

Addo KA, Jayson-Quashigah PN, Codjoe SNA, Martey F (2018) Drone as a tool for coastal flood monitoring in the Volta Delta, Ghana. Geoenviron Disasters 5(1):17

Blossier B, Bryan KR, Daly CJ, Winter C (2017) Spatial and temporal scales of shoreline morphodynamics derived from video camera observations for the island of Sylt, German Wadden Sea. Geo-Mar Lett 37(2):111-123. https://doi.org/10.1007/s00367-016-0461-7

Casella E, Rovere A, Pedroncini A et al (2014) Study of wave runup using numerical models and low-altitude aerial photogrammetry: a tool for coastal management. Estuar Coast Shelf Sci 149:160-167. https://doi.org/10.1016/j.ecss.2014.08.012

Casella E, Rovere A, Pedroncini A, Stark CP, Casella M, Ferrari M, Firpo M (2016) Drones as tools for monitoring beach topography changes in the Ligurian Sea (NW Mediterranean). Geo-Marine Lett 36:151163. https://doi.org/10.1007/s00367-016-0435-9

Casella E, Collin A, Harris D, Ferse S, Bejarano S, Parravicini V, Hench JL, Rovere A (2017) Mapping coral reefs using consumer-grade drones and structure from motion photogrammetry techniques. Coral Reefs 36:269-275. https://doi.org/10.1007/s00338-0161522-0

Chen B, Yang Y, Wen H et al (2018) High-resolution monitoring of beach topography and its change using unmanned aerial vehicle imagery. Ocean Coast Manag 160:103-116. https://doi.org/10. 1016/j.ocecoaman.2018.04.007

Chikhradze N (2015) Close range photogrammetry in the survey of the coastal area geoecological conditions (on the example of Portugal). Earth Sci 4:35. https://doi.org/10.11648/j.earth.s.2015040501.17

Chirayath V, Earle S (2016) Drones that see through waves - preliminary results from airborne fluid lensing for centimetre-scale aquatic conservation. Aquat Conserv Mar Freshw Ecosyst Special Is:237-250. https://doi.org/10.1002/aqc.2654

Conlin M, Cohn N, Ruggiero P (2018) A quantitative comparison of lowcost structure from motion ( $\mathrm{SfM}$ ) data collection platforms on beaches and dunes. J Coast Res 34:1341. https://doi.org/10.2112/ jcoastres-d-17-00160.1

Dąbski M, Zmarz A, Pabjanek P, Korczak-Abshire M, Karsznia I, Chwedorzewska KJ (2017) UAV-based detection and spatial analyses of periglacial landforms on Demay Point (King George Island, South Shetland Islands, Antarctica). Geomorphology 290:29-38

Dohner SM, Trembanis AC, Miller DC (2016) A tale of three storms: morphologic response of Broadkill Beach, Delaware, following Superstorm Sandy, Hurricane Joaquin, and Winter Storm Jonas. Shore Beach 84:3-9

Duo E, Chris Trembanis A, Dohner S et al (2018) Local-scale post-event assessments with GPS and UAV-based quick-response surveys: a pilot case from the Emilia-Romagna (Italy) coast. Nat Hazards Earth Syst Sci 18:2969-2989. https://doi.org/10.5194/nhess-182969-2018

Eisenbeiss H (2009) UAV Photogrammetry Ph.D. Thesis, ETH Zürich, Zürich, Switzerland

Elsner P, Dornbusch U, Thomas I et al (2018) Coincident beach surveys using UAS, vehicle mounted and airborne laser scanner: point cloud inter-comparison and effects of surface type heterogeneity on elevation accuracies. Remote Sens Environ 208:15-26. https://doi.org/10. 1016/j.rse.2018.02.008

Eltner A, Kaiser A, Castillo C, Rock G, Neugirg F, Abellan A (2015) Image-based surface reconstruction in geomorphometry - merits, limits and developments of a promising tool for geoscientists. Earth Surf Dyn Discuss 1445-1508. https://doi.org/10.5194/ esurfd-3-1445-2015

Forlani G, Dall'Asta E, Diotri F, Cella UM, Roncella R, Santise M (2018) Quality assessment of DSMs produced from UAV flights georeferenced with on-board RTK positioning. Remote Sens 10(2):311

Gonçalves JA, Henriques R (2015) UAV photogrammetry for topographic monitoring of coastal areas. ISPRS J Photogramm Remote Sens 104:101-111. https://doi.org/10.1016/j.isprsjprs.2015.02.009

Gonçalves GR, Pérez JA, Duarte J (2018) Accuracy and effectiveness of low cost UASs and open source photogrammetric software for foredunes mapping. Int J Remote Sens 39:5059-5077. https://doi. org/10.1080/01431161.2018.1446568

Guillot B, Pouget F (2015) UAV application in coastal environment, example of the Oleron island for dunes and dikes survey. Int Arch Photogramm Remote Sens Spat Inf Sci - ISPRS Arch 40:321-326. https://doi.org/10.5194/isprsarchives-XL-3-W3-321-2015

Guillot B, Castelle B, Marieu V et al (2018) UAV monitoring of 3-year Foredune Partial Recovery from a Severe Winter: Truc Vert Beach, SW France. J Coast Res 85:276-280. https://doi.org/10.2112/SI85056.1

Guisado-Pintado E, Jackson DWT, Rogers D (2019) 3D mapping efficacy of a drone and terrestrial laser scanner over a temperate beachdune zone. Geomorphology 328:157-172. https://doi.org/10.1016/j. geomorph.2018.12.013

Harley MD, Turner IL, Short AD, Ranasinghe R (2010) Assessment and integration of conventional, RTK-GPS and image-derived beach survey methods for daily to decadal coastal monitoring. Coast Eng 58:194-205

Harley MD, Turner IL, Short AD et al (2015) Four decades of coastal monitoring at Narrabeen-Collaroy Beach: the past, present and future of this unique dataset. Coast Ports 2015:1-6

Harwin S, Lucieer A (2012) Assessing the accuracy of georeferenced point clouds produced via multi-view stereopsis from unmanned aerial vehicle (UAV) imagery. Remote Sens 4(6):1573-1599

Harwin S, Lucieer A, Osborn J (2015) The impact of the calibration method on the accuracy of point clouds derived using unmanned aerial vehicle multi-view stereopsis. Remote Sens 7:11933-11953. https://doi.org/10.3390/rs70911933

Ierodiaconou D, Schimel AC, Kennedy DM (2016) A new perspective of storm bite on sandy beaches using unmanned aerial vehicles. Zeitschrift für Geomorphologie Suppl Issues 60(3):123-137

James MR, Robson S (2014) Mitigating systematic error in topographic models derived from UAV and ground-based image networks. Earth Surf Process Landf 39:1413-1420. https://doi.org/10.1002/esp.3609

Jeong E, Park J-Y, Hwang C-S (2018) Assessment of UAV photogrammetric mapping accuracy in the beach environment. J Coast Res 85 : 176-180. https://doi.org/10.2112/si85-036.1

Joyce KE, Duce S, Leahy SM et al (2018) Principles and practice of acquiring drone-based image data in marine environments. Mar Freshw Res 70:952-963

King S, Leon JX, Mulcahy M, Jackson LA, Corbett BB (2017) Condition survey of coastal structures using UAV and photogrammetry. In: Australasian Coasts \& Ports conference, Cairns, 21-23 June 2017

Laporte-Fauret Q, Marieu V, Castelle B et al (2019) Low-cost UAV for high-resolution and large-scale coastal dune change monitoring using photogrammetry. J Mar Sci Eng 7:63. https://doi.org/10. 3390/jmse7030063

Long N, Millescamps B, Guillot B et al (2016a) Monitoring the topography of a dynamic tidal inlet using UAV imagery. Remote Sens 8:118. https://doi.org/10.3390/rs8050387

Long N, Millescamps B, Pouget F, et al (2016b) Accuracy assessment of coastal topography derived from UAV images. Int Arch Photogramm Remote Sens Spat Inf Sci - ISPRS Arch 2016-Janua: 1127-1134. doi: https://doi.org/10.5194/isprsarchives-XLI-B1$1127-2016$

Lowe MK, Adnan FAF, Hamylton SM et al (2019) Assessing reef-island shoreline change using UAV-derived orthomosaics and digital surface models. Drones 3:44. https://doi.org/10.3390/drones3020044 
Lu CH (2016) Applying UAV and photogrammetry to monitor the morphological changes along the beach in Penghu islands. Int Arch Photogramm Remote Sens Spat Inf Sci - ISPRS Arch 41:11531156. https://doi.org/10.5194/isprsarchives-XLI-B8-1153-2016

Mancini F, Dubbini M, Gattelli M, Stecchi F, Fabbri S, Gabbianelli G (2013) Using unmanned aerial vehicles (UAV) for high-resolution reconstruction of topography: the structure from motion approach on coastal environments. Remote Sens 5(12):6880-6898

Matsuba Y, Sato S, Hadano K (2017) Rapid change in coastal morphology due to sand-bypassing captured by UAV-based monitoring system. Coastal Dynamics (Vol. 15291539)

Moloney JG, Hilton MJ, Sirguey P, Simons-Smith T (2018) Coastal dune surveying using a low-cost remotely piloted aerial system (RPAS). J Coast Res 345:1244-1255. https://doi.org/10.2112/jcoastres-d-1700076.1

Nikolakopoulos KG, Kozarski D, Kogkas S (2017) Coastal areas mapping using UAV photogrammetry. 23. doi: https://doi.org/10.1117/ 12.2278121

Pádua L, Hruška J, Bessa J et al (2017) Multi-temporal analysis of forestry and coastal environments using UASs. Remote Sens 10:1-21. https://doi.org/10.3390/rs 10010024

Papakonstantinou A, Topouzelis K, Pavlogeorgatos G (2016) Coastline zones identification and 3D coastal mapping using UAV spatial data. ISPRS Int J Geo-Information 5:75. https://doi.org/10.3390/ ijgi5060075

Papakonstantinou A, Topouzelis K, Doukari M (2017) UAS close range remote sensing for mapping coastal environments. 1044418:35. doi: https://doi.org/10.1117/12.2278988

Pitman SJ, Hart DE, Katurji MH (2019) Application of UAV techniques to expand beach research possibilities: a case study of coarse clastic beach cusps. Cont Shelf Res 184:44-53

Ruessink BG, Arens SM, Kuipers M, Donker JJA (2018) Coastal dune dynamics in response to excavated foredune notches. Aeolian Res 31:3-17. https://doi.org/10.1016/j.aeolia.2017.07.002

Ryan JC, Hubbard AL, Box JE, Todd J, Christoffersen P, Carr JR, Holt TO, Snooke N (2015) UAV photogrammetry and structure from motion to assess calving dynamics at store glacier, a large outlet draining the Greenland ice sheet. Cryosphere 9:1-11

Sari NM, Nugroho JT, Chulafak GA, Kushardono D (2018) Study of 3D bathymetry modelling using LAPAN surveillance unmanned aerial vehicle 02 (LSU-02) photo data with stereo photogrammetry technique, Wawaran Beach, Pacitan, East Java, Indonesia. IOP Conf Ser Earth Environ Sci 149. https://doi.org/10.1088/1755-1315/149/1/ 012065

Scarelli FM, Cantelli L, Barboza EG et al (2016) Natural and anthropogenic coastal system comparison using DSM from a low cost UAV survey (Capão novo, RS/Brazil). J Coast Res 75:1232-1236. https:// doi.org/10.2112/si75-247.1
Scarelli FM, Sistilli F, Fabbri S et al (2017) Seasonal dune and beach monitoring using photogrammetry from UAV surveys to apply in the ICZM on the Ravenna coast (Emilia-Romagna, Italy). Remote Sens Appl Soc Environ 7:27-39. https://doi.org/10.1016/j.rsase. 2017.06.003

Seymour AC, Ridge JT, Rodriguez AB, Newton E, Dale J, Johnston DW (2017) Deploying fixed wing unoccupied aerial systems (UAS) for coastal morphology assessment and management. J Coast Res 34(3):704-717

Sturdivant E, Lentz E, Thieler ER, Farris A, Weber K, Remsen D, Miner S, Henderson R (2017) UAS-SfM for coastal research: geomorphic feature extraction and land cover classification from high-resolution elevation and optical imagery. Remote Sens 9(10):1020

Su L, Gibeaut J (2017) Using UAS hyperspatial RGB imagery for identifying beach zones along the South Texas coast. Remote Sens 9. https://doi.org/10.3390/rs9020159

Taddia Y, Corbau C, Zambello E, Pellegrinelli A (2019) UAVs for structure-from-motion coastal monitoring: a case study to assess the evolution of embryo dunes over a two-year time frame in the po river delta, Italy. Sensors (Switzerland) 19. https://doi.org/10. 3390/s19071717

Talavera L, Del Río L, Benavente J et al (2018a) UAS as tools for rapid detection of storm-induced morphodynamic changes at Camposoto beach, SW Spain. Int J Remote Sens 39:5550-5567. https://doi.org/ 10.1080/01431161.2018.1471549

Talavera L, del Río L, Benavente J et al (2018b) UAS \& S f M-based approach to monitor overwash dynamics and beach evolution in a sandy spit. J Coast Res 85:221-225. https://doi.org/10.2112/si85045.1

Topouzelis K, Papakonstantinou A, Doukari M (2017) Coastline change detection using unmanned aerial vehicles and image processing technique. Fresenius Environ Bull 26:5564-5571

Torres-Freyermuth A, Medellín G, Mendoza ET et al (2019) Morphodynamic response to low-crested detached breakwaters on a sea breeze-dominated coast. Water (Switzerland):11. https://doi. org/10.3390/w11040635

Turner IL, Harley MD, Drummond CD (2016) UAVs for coastal surveying. Coast Eng 114:19-24

Yoo CI, Oh TS (2016) Beach volume change using UAV photogrammetry Songjung beach, Korea. Int Arch Photogramm Remote Sens Spat Inf Sci - ISPRS Arch 41:1201-1205. https://doi.org/10.5194/ isprsarchives-XLI-B8-1201-2016

Publisher's note Springer Nature remains neutral with regard to jurisdictional claims in published maps and institutional affiliations. 